\title{
Perancangan Alat Bantu untuk Liquid Container Berdasarkan Penilaian Rapid Entire Body Assessment dan Washington State Checklist
}

\author{
Risya Rahmasari Kosasih, Sri Martini, Mira Rahayu \\ Jurusan Teknik Industri, Fakultas Rekayasa Industri, Universitas Telkom, Jalan Telekomunikasi No.1, Kab. Bandung, Jawa \\ Barat, Indonesia
}

\section{ARTICLE INFORMATION}

Article history:

Received: May 30, 2019

Revised: June 28, 2019

Accepted: July 11, 2019

\section{Kata Kunci}

Alat Bantu

Liquid Container

Musculoskeletal Disorders (MSDs)

Rapid Entire Body Assessment (REBA)

Washington State Checklist (WSC)

\section{Keywords:}

Material Handling

Liquid Container

Musculoskeletal Disorders (MSDs)

Rapid Entire Body Assessment (REBA)

Washington State Checklist (WSC)

${ }^{*}$ Corresponding Author

Risya Rahmasari Kosasih

E-mail: risya.rahmasari@gmail.com

\section{A B S T R A K}

Permasalahan pada penelitian kali ini ada pada penggunaan liquid container yang digunakan sebagai penampung bulk kosmetik yang akan dipindahkan dari ruang WIP ke ruang pengemasan produk. Berdasarkan aktivitas pemindahan tersebut, ditemukan adanya risiko terhadap paparan Musculoskeletal Disorders (MSDs) yang dianalisis menggunakan Rapid Entire Body Assessment (REBA) dan Washington State Checklist (WSC). Penelitian ini bertujuan untuk merancang alat bantu untuk liquid container yang lebih ergonomis agar dapat mengurangi dampak MSDs pada pekerjanya. Perancangan ulang alat bantu ini menggunakan konsep Reverse Engineering. Desain alat bantu pengangkut liquid container yang baru secara simulasi mampu menurunkan skor REBA dengan nilai WSC kategori risiko rendah terhadap paparan MSDs berdasarkan kategori overall work environment.

\section{A B S T R A C T}

The problem in this research is the use of liquid containers, which use as bulk cosmetic containers, which will be move from the WIP room to the product packaging room. Based on these transfer activities, there was a risk of exposure to Musculoskeletal Disorders (MSDs), which were analyzed using Rapid Entire Body Assessment (REBA) and Washington State Checklist (WSC). This study aims to design a tool for a more ergonomic liquid container to reduce the impact of MSDs on workers. Redesigning this tool uses the concept of Reverse Engineering. The design of the new liquid container transporter simulation can reduce REBA score with a WSC value of low-risk category for MSDs exposure based on the overall work environment category.

This is an open access article under the CC-BY-NC-SA license.

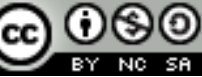

(C) 2019 Some rights reserved

\section{PENDAHULUAN}

PT XYZ merupakan salah satu perusahaan perawatan kulit dan kosmetik yang memiliki lingkungan nyaman dan bersih dengan beberapa section pada lantai produksinya yaitu cream, powder, dan liquid. Identifikasi awal pada proses produksi, ditemukan kesalahan penggunaan alat bantu pada proses liquid. Padahal, alat bantu sangat berkaitan dengan aliran produksi dan memiliki pengaruh langsung pada waktu transit, penggunaan sumber daya, dan tingkat layanan [1]. Pada proses liquid, operator menggunakan liquid container untuk membawa cairan dari satu stasiun kerja ke stasiun kerja lainnya. Pada studi kasus di PT XYZ, Liquid container dengan muatan 
100 - $130 \mathrm{~kg}$ dipindahkan dari ruangan Work In Process (WIP) ke ruangan pengemasan dengan didorong menggunakan tangan kosong oleh salah satu operatornya. Akibat aktivitas tersebut, operator sering mengalami pegal di bagian pinggul, punggung, dan lengan atasnya. Menurut Gentzler dan Stader [2], cedera punggung adalah salah satu gangguan muskuloskeletal yang paling mahal di negara-negara industri.

Berdasarkan permasalahan pada proses liquid, penelitian ini melakukan penilaian Rapid Entire Body Assessment (REBA) dan Washington State Checklist Assessment Tool (WSC) pada aktivitas pemindahan liquid container yang dilakukan operator (Gambar 1) untuk mengetahui tingkat risiko terhadap paparan MSDs. REBA merupakan salah satu alat penilaian ergonomi yang menggunakan proses sistematis untuk mengevaluasi MSDs postural seluruh tubuh dan risiko yang terkait dengan tugas-tugas pekerjaan. Musculoskeletal Disorders (MSDs) merupakan penyakit pada persendian, saraf, dan rongga gerak manusia [3]. Penilaian REBA dirancang untuk memberikan skor pada masing-masing daerah tubuh [4], yaitu: Grup A yang terdiri dari neck, trunk, legs, dan tambahan penilaian force/load; Grup B yang terdiri dari upper arm, lower arm, wrist, dan tambahan penilaian coupling; dan Activity score yang merupakan penilaian aktivitas yang dialami tubuh. REBA dikembangkan untuk menilai postur kerja yang melibatkan penggunaan seluruh tubuh, baik secara statis, dinamis, cepat berubah atau tidak stabil, maupun terjadinya manual handling [5]. WSC merupakan suatu sistem penilaian ergonomi sebagai bagian dari upaya untuk mengendalikan paparan bahaya MSDs di tempat kerja [6].

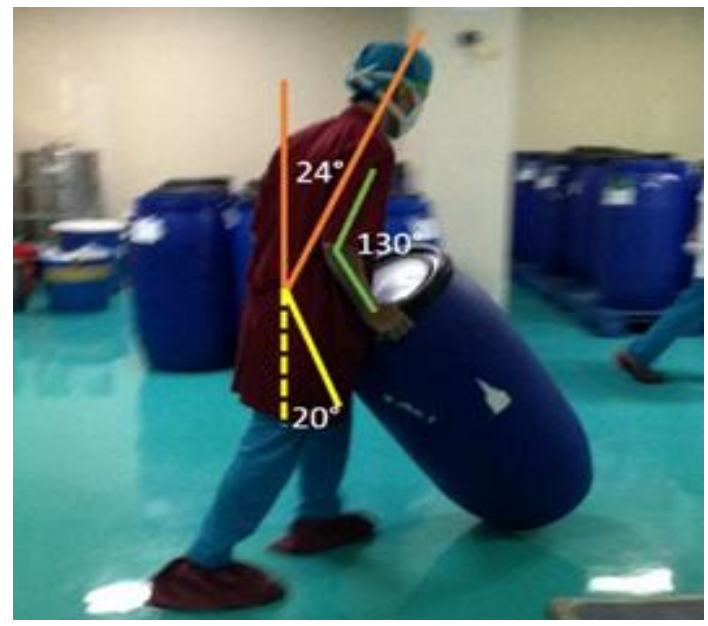

Gambar 1. Operator tanpa menggunakan alat bantu
Berdasarkan analisis awal, pada aktivitas pemindahan liquid container dengan tangan kosong tersebut (Gambar 1), didapatkan nilai REBA 9 poin yang mengindikasikan risiko tinggi dan membutuhkan penerapan perubahan serta nilai WSC yang mengindikasikan risiko sedang pada kategori overall work environment.

Penelitian ini bertujuan untuk merancang alat bantu baru agar operator dapat bekerja lebih ergonomis berdasarkan nilai postur REBA dan WSC yang dihasilkan. Perancangan alat bantu ini didukung dengan menggunakan metode Reverse Engineering sebagai hasil pengolahan data. Metode Reverse Engineering di industri merupakan suatu langkah meniru produk yang sudah ada sebagai dasar untuk merancang produk baru yang sejenis dengan merubah desain, memperkecil kelemahan, dan meningkatkan keunggulan produk dari para pendahulunya [7].

\section{METODE PENELITIAN}

Metode penelitian yang digunakan pada penelitian kali ini adalah metode Reverse Engineering yang digambarkan melalui dua diagram, yaitu Gambar 2 yang menunjukkan mengenai model konseptual penelitian dan Gambar 3 yang menunjukkan sistematika pemecahan masalah. Cakupan utama Reverse Engineering adalah melakukan produksi ulang objek yang sudah ada dengan menganalisis dimensi, fitur, bentuk, dan sifat sehingga data dan informasi yang dikumpulkan harus diubah menjadi pengetahuan produk yang berkaitan di tingkat sistem, perwujudan, dan detail [8].

Gambar 2 merupakan penggambaran model konseptual dari penelitian ini. Penelitian ini berfokus pada perancangan alat bantu pengangkut liquid container dengan perbaikan nilai REBA dan WSC yang didapatkan. Aktivitas pemindahan liquid container di perusahaan diindikasi memiliki risiko MSDs, karena itu para penggunanya kerap kali merasa kelelahan serta nyeri otot \& sendi terutama di bagian punggung. Hal ini mendukung salah satu pernyataan Chang et, al. [9] dalam tulisannya, bahwa MSDs dikatakan dapat mengakibatkan menurunnya produktivitas dan tingkat presensi pekerja serta dapat meningkatkan biaya kompensasi kesehatan yang harus dikeluarkan oleh perusahaan. Perancangan dilakukan dengan menggunakan metode Reverse Engineering dan Solidworks sebagai software perancangan 3D. Metode ini digunakan karena perancangan produk usulan dilakukan berdasarkan 


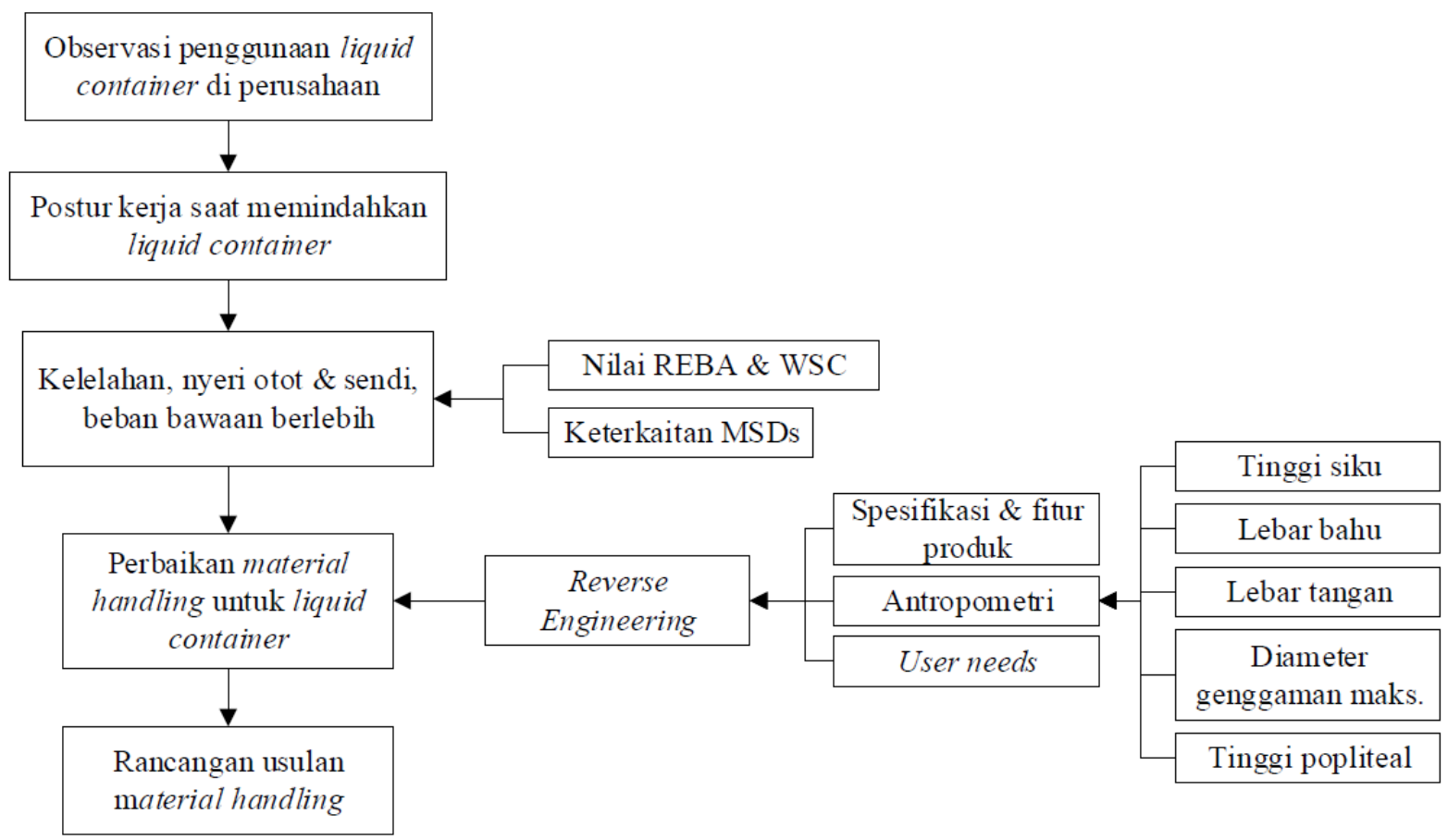

Gambar 2. Model konseptual

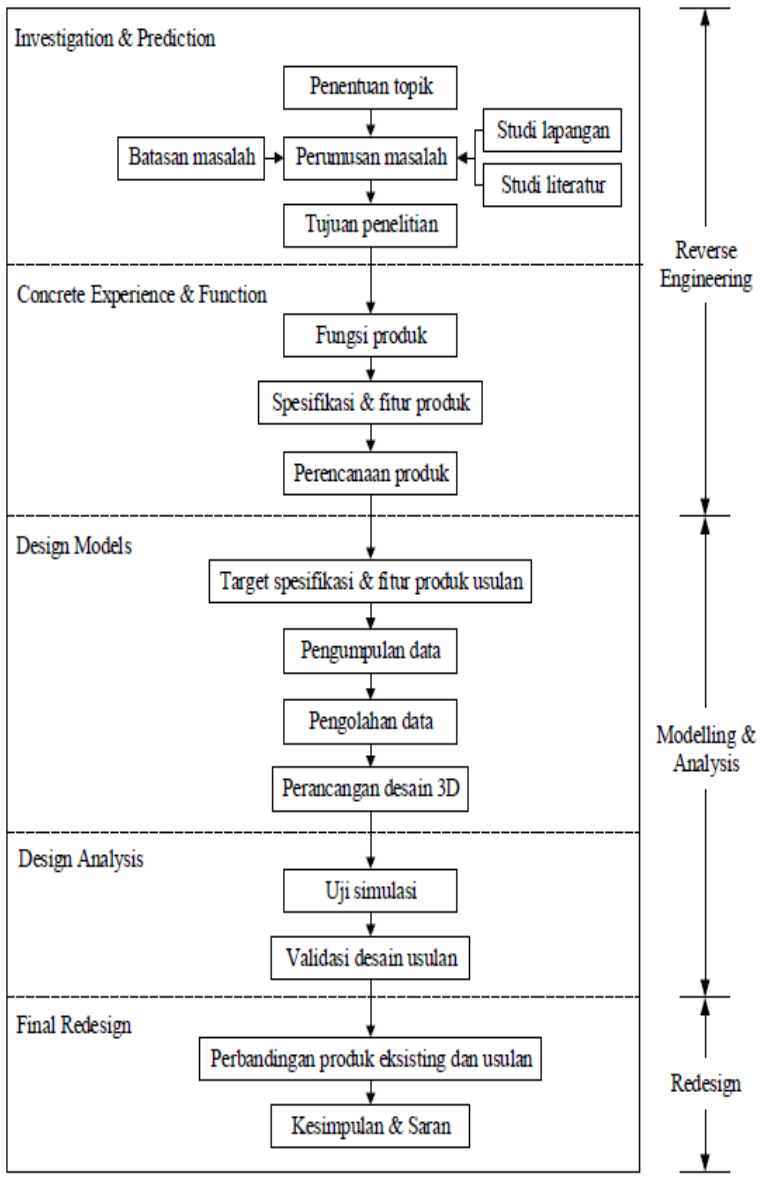

Gambar 3. Sistematika pemecahan masalah benchmarking dan pengembangan konsep dari produk-produk yang sudah ada. Keluaran yang diharapkan pada perancangan ini adalah menurunnya nilai REBA dan WSC yang mengindikasikan risiko paparan MSDs pada operator. Dengan penggunaan produk usulan, operator dapat memperbaiki postur kerjanya menjadi lebih baik. Sehingga, sistematika pemecahan masalah yang dilalui adalah seperti pada Gambar 3. Sistematika ini merupakan pengembangan dari metodologi Otto \& Wood [10]

\section{Investigation \& Prediction}

Pada tahap ini dilakukan investigasi dan prediksi produk. Tahap ini dapat dikatakan sebagai tahap awal penelitian. Pemahaman dan observasi lapangan dengan saksama dibutuhkan pada tahap ini guna memperoleh permasalahan yang terjadi dan menentukan tujuan serta sistematis penyelesaian masalah dari penelitian yang diadakan. Pada tahap ini dilakukan beberapa hal berikut:

1. Penentuan topik

Topik yang ditentukan pada penelitian kali ini adalah perancangan alat bantu untuk liquid container dengan menggunakan metode Reverse Engineering berdasarkan penilaian ergonomi untuk mencegah risiko MSDs pada operator. Ergonomi merupakan salah satu pendekatan utama yang digunakan pada penelitian ini, terutama pada tahap design models nantinya. 
Ergonomi merupakan disiplin ilmu yang digunakan untuk mencapai penyesuaian antara pekerjaan dengan manusia secara optimal [11] dengan tujuan mengurangi kesalahan, meningkatkan fleksibilitas dan kinerja sistem, meningkatkan keselamatan manusia, dan meningkatkan produktivitas [12], [13].

2. Perumusan masalah

Setelah mengetahui topik dan tema yang mendasari penelitian ini, selanjutnya adalah perumusan masalah pada topik tersebut, yaitu untuk mengetahui perancangan ulang alat bantu pengangkut liquid container yang lebih ergonomis dengan menggunakan metode Reverse Engineering. Rumusan masalah ini didukung oleh studi lapangan dan studi literatur yang telah dilalui peneliti dan penentuan batasan masalah untuk menjaga agar tujuan pemecahan masalah dapat tercapai. Rumusan masalah juga didasari oleh hasil perhitungan yang telah membuktikan bahwa penggunaan produk tidak optimal untuk digunakan, yaitu berupa perhitungan nilai REBA dan WSC.

\section{Tujuan penelitian}

Tujuan dari penelitian ini adalah mengusulkan produk rancangan berupa alat bantu untuk liquid container yang lebih ergonomis dengan menggunakan metode Reverse Engineering. Selain itu, MSDs merupakan salah satu objek yang berusaha dicegah pada penggunaan produk/alat bantu. Pada tahap design models nantinya, produk dirancang untuk dapat meminimasi hingga mencegah MSDs menyerang penggunanya. Musculoskeletal Disorders (MSDs) adalah gangguan yang mempengaruhi gerakan manusia dalam melakukan pekerjaan yang berakibat pada rasa sakit dan kecacatan dalam jangka panjang [14]. Untuk mengetahui risiko MSDs sendiri, dapat diketahui melalui penilaian ergonomi di antaranya REBA dan WSC.

\section{Concrete Experience \& Function}

Pada tahap ini dilakukan pencarian data pada fungsi beserta spesifikasi dan fitur produk yang sudah ada. Tahap ini dapat disebut sebagai tahap data acuan. Hasil akhir dari tahap ini adalah perencanaan produk usulan. Tahap ini meneliti fungsi, spesifikasi, dan cara kerja alat bantu existing.

\section{Design Models}

Pada tahap ini dilakukan perancangan produk atau disebut sebagai tahap pengolahan data. Tahapan yang dilalui pada bagian ini adalah sebagai berikut:

1. Target spesifikasi \& fitur produk usulan

Penentuan target spesifikasi dan fitur produk usulan yang dapat mengoptimalkan fungsi dari produk existing, yaitu dengan merancang produk yang lebih ergonomis dan menambahkan beberapa fitur tambahan.

\section{Pengumpulan data}

Pada tahap ini dikumpulkan data-data yang dapat menunjang perancangan produk usulan, di antaranya ukuran antropometri operator yang digunakan untuk ukuran produk usulan. Antropometri merupakan pendekatan lainnya yang digunakan pada design models. Antropometri merupakan model pengukuran tubuh untuk menemukan perbedaan ukuran pada setiap individu atau kelompoknya. Penerapan antropometri dalam ergonomi umumnya mencakup desain dan tata letak ruang tempat orang tinggal dan bekerja, dengan referensi khusus untuk pertimbangan antropometri [15], seperti jangkauan [16], postur [17], maupun kekuatan manusia [18]. Kebanyakan data antropometri disajikan dalam bentuk persentil. Persentil merupakan rentang nilai tertentu yang digunakan sebagai pertimbangan ukuran yang digunakan dalam suatu perancangan. Antropometri yang didata pada penelitian ini di antaranya adalah ukuran tinggi siku, lebar bahu, lebar tangan, diameter genggaman maksimal, dan tinggi popliteal. Selain itu dikumpulkan data kebutuhan pengguna (user needs) yang digunakan sebagai pertimbangan perancangan produk, dan alur produksi yang melibatkan penggunaan liquid container.

\section{Pengolahan data}

Pada tahap ini, data yang diperoleh diolah untuk mendapatkan nilai REBA dan WSC yang lebih baik dengan merancang suatu alat bantu baru. Pengolahan data dilakukan melalui beberapa tahap, yaitu concept selection, concept screening, dan concept scoring [19]. Dalam pengolahan data ini, alternatif rancangan produk dibuat untuk menyesuaikan ukuran antropometri dan kebutuhan penggunanya. Antropometri digunakan sebagai penyedia data untuk mendesain dan membentuk suatu alat pendukung kerja, pekerjaan itu sendiri, dan lingkungan kerjanya [20].

\section{Perancangan desain 3D}

Rancangan produk usulan tersebut kemudian diolah menggunakan software desain 3D, yaitu Solidworks.

\section{Design Analysis}

Pada tahap ini dilakukan analisis terhadap desain usulan. Tahap ini memperhatikan uji simulasi dan validasi desain usulan. Analisis REBA dan WSC dilakukan kembali untuk mengetahui tingkat risiko yang sekiranya akan dialami operator. Analisis ini dibantu dengan menggunakan software simulasi pendukung, yaitu Catia dan 
Excel Sistem Perhitungan WSC oleh Washington State Department of Labor \& Industries.

\section{Final Redesign}

Pada tahap analisis akhir dan kesimpulan, dilakukan pengamatan terhadap perbandingan aktivitas existing dan usulan. Perbandingan yang diperhatikan dapat melalui fitur atau fungsi tambahan produk, dimensi, dan tentunya perbandingan nilai REBA dan WSC yang menjadi fokus utama penelitian. Kemudian setelah pengamatan dilakukan, diambil kesimpulan dan saran terhadap perancangan usulan produk.

\section{HASIL DAN PEMBAHASAN}

\section{Investigation \& Prediction}

Pada tahap ini dilakukan pengumpulan data untuk memastikan batasan masalah pada pengembangan produk serta memprediksi fungsi produk berdasarkan aktivitas dan data yang tersedia di lapangan [21]. Data yang dikumpulkan adalah dimensi serta bobot liquid container, postur kerja operator existing, ukuran antropometri operator terkait, dan atribut kebutuhan yang diinterpretasikan menjadi need statement atau kebutuhan dan harapan pengguna terhadap suatu produk. Need statement didapatkan dari proses observasi lapangan dan wawancara dengan para penggunanya. Sehingga need statement yang dihasilkan adalah sebagai berikut:

a. Produk memiliki ukuran yang proporsional;

b. Produk mudah digunakan;

c. Produk nyaman digunakan;

d. Produk aman digunakan;

e. Produk dapat bermanuver dengan baik;

f. Produk dapat meminimasi penggunaan tenaga;

g. Penggunaan produk dapat meminimasi penyakit akibat kerja.

\section{Concrete Experience \& Function}

Pada tahap ini dilakukan dekomposisi produkproduk existing untuk dapat membantu mendefinisikan komponen-komponen yang ada yang mungkin dapat dikembangkan atau dihilangkan dalam pengembangan produk usulan [22]. Reverse Engineering adalah salah satu metodologi yang digunakan untuk mendapatkan informasi dari komponen suatu alat agar dapat memperbaikinya [23]. Selain itu pada tahap ini need statement diinterpretasikan untuk mendapatkan metrik produk yang merupakan karakteristik pembentuk spesifikasi teknis, seperti yang ditunjukkan pada Tabel 1.

Setelah mendapatkan metrik produk, target spesifikasi teknis ditentukan dengan penyesuaian kebutuhan pengguna dan didukung oleh proses benchmarking untuk kepentingan pengembangan produk. Sehingga didapatkan spesifikasi teknis seperti yang ditunjukkan pada Tabel 2.

Tabel 1. Metrik produk

\begin{tabular}{|c|c|c|}
\hline Aspek & $\begin{array}{c}\text { Need } \\
\text { Statement }\end{array}$ & Metrik Produk \\
\hline \multirow{3}{*}{ Keandalan } & \multirow{4}{*}{$\begin{array}{l}\text { Produk } \\
\text { memiliki } \\
\text { ukuran yang } \\
\text { proporsional } \\
\text { Produk dapat } \\
\text { bermanuver } \\
\text { dengan baik } \\
\text { Produk } \\
\text { mudah } \\
\text { digunakan }\end{array}$} & $\begin{array}{l}\text { Dimensi MH } \\
\text { (berdasarkan } \\
\text { antropometri) }\end{array}$ \\
\hline & & Bobot MH \\
\hline & & Dimensi MH \\
\hline \multirow{3}{*}{ Kemudahan } & & $\begin{array}{l}\text { Step interaksi } \\
\text { dengan } \mathrm{MH}\end{array}$ \\
\hline & \multirow{2}{*}{$\begin{array}{l}\text { Produk dapat } \\
\text { meminimasi } \\
\text { penggunaan } \\
\text { tenaga }\end{array}$} & Bobot MH \\
\hline & & $\begin{array}{l}\text { Step interaksi } \\
\text { dengan } \mathrm{MH}\end{array}$ \\
\hline \multirow{3}{*}{ Kenyamanan } & $\begin{array}{l}\text { Produk } \\
\text { nyaman } \\
\text { digunakan }\end{array}$ & $\begin{array}{l}\text { Dimensi MH } \\
\text { (berdasarkan } \\
\text { antropometri) } \\
\text { Bobot } \mathrm{MH}\end{array}$ \\
\hline & \multirow{2}{*}{$\begin{array}{l}\text { Penggunaan } \\
\text { produk dapat } \\
\text { meminimasi } \\
\text { penyakit } \\
\text { akibat kerja }\end{array}$} & Bobot $\mathrm{MH}$ \\
\hline & & Skor MSDs \\
\hline
\end{tabular}

Tabel 2. Target spesifikasi teknis

\begin{tabular}{llcc}
\hline \multicolumn{2}{c}{ Metrik Produk } & Nilai & Satuan \\
\hline \multirow{3}{*}{ Dimensi MH } & Panjang MH & $\geq 44.6$ & $\mathrm{~cm}$ \\
& Lebar MH & $\geq 52$ & $\mathrm{~cm}$ \\
& Tinggi MH & \pm 116 & $\mathrm{~cm}$ \\
Skor MSDs & Skor REBA & $<9$ & poin \\
Bobot MH & Skor WSC & low & kategori \\
Setup time MH & $<100$ & $\mathrm{~kg}$ \\
& $<11$ & tahap \\
\hline
\end{tabular}

\section{Design Models}

Setelah melalui beberapa tahapan sebelumnya, langkah selanjutnya adalah melakukan perancangan model produk usulan dengan melalui beberapa proses, diantaranya concept selection, concept screening, dan concept scoring, menyesuaikan dengan spesifikasi teknis yang telah ditentukan.

Pada tahap concept selection, beberapa pilihan alternatif dirumuskan melalui matriks morfologi 
Tabel 3. Matriks morfologi produk

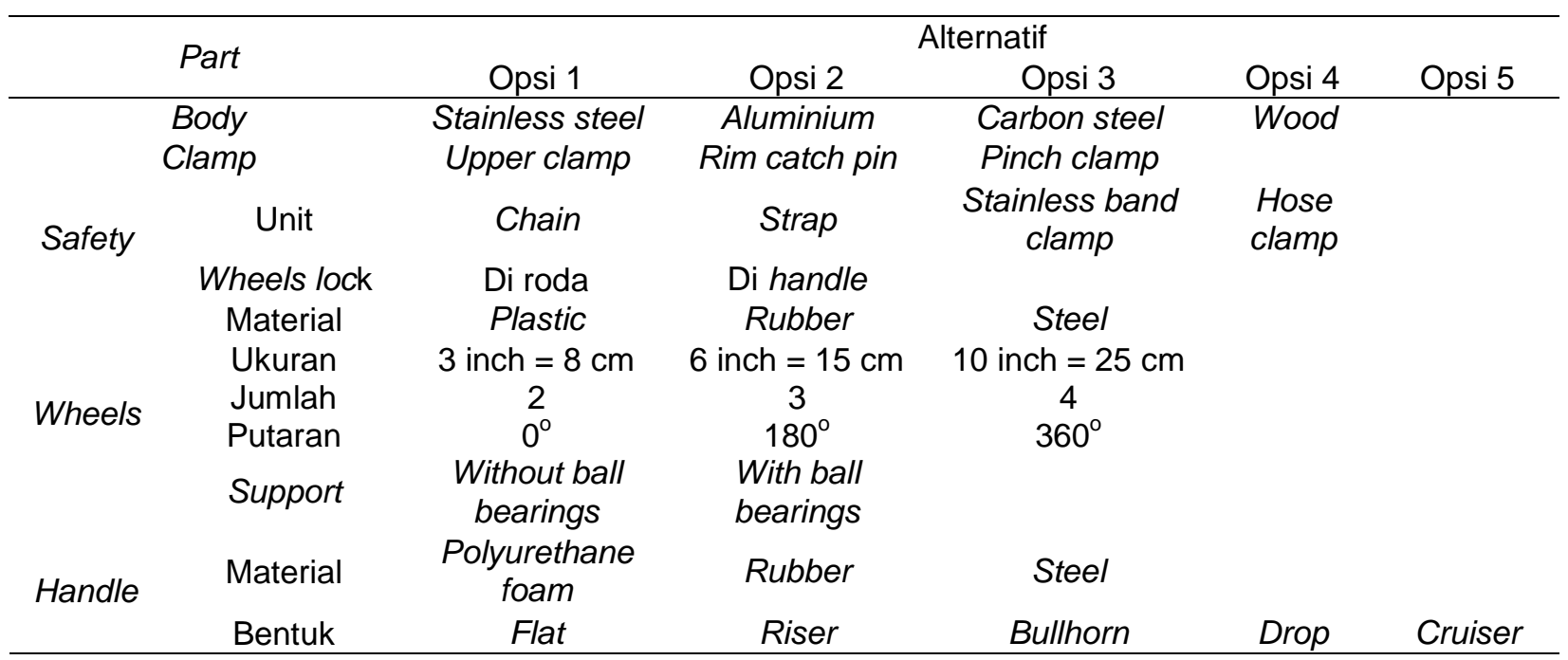

produk untuk menentukan rancangan alat bantu usulan [24]. Alternatif pilihan dipertimbangkan melalui need statement dari pengguna yang terlibat. Berikut merupakan hasil alternatif terpilih setelah melalui proses pemilihan konsep.

Setelah concept selection telah dilakukan, maka selanjutnya adalah melakukan concept screening dan concept scoring. Concept screening bertujuan untuk mengerucutkan konsep terpilih dengan melakukan penilaian terhadap kebutuhan penggunanya. Sehingga, konsep terbaik akan terpilih. Sementara pada concept scoring penilaian lanjutan dilakukan guna mengetahui relativitas rancangan terhadap tingkat kepentingan yang diharapkan penggunanya sehingga didapatkan konsep akhir.

Tabel 4. Alternatif terpilih

\begin{tabular}{llc}
\hline & Part & Konsep III \\
\hline $\begin{array}{l}\text { Body } \\
\text { Clamp }\end{array}$ & & Stainless steel \\
Safety & Rim catch pin \\
& Wheels lock & Chain \\
& Material & Di handle \\
\multirow{4}{*}{ Wheels } & Ukubber & 10 inch $=25 \mathrm{~cm}$ \\
& Jumlah & 4 \\
& Putaran & $360^{\circ}$ \\
& Support & With ball bearings \\
Handle & Material & Polyurethane foam \\
& Bentuk & Flat \\
\hline
\end{tabular}

Berdasarkan pengolahan data yang telah dilakukan, terpilihlah konsep III karena memiliki total skor yang paling besar yaitu 4,014 . Total skor tersebut mencerminkan bahwa produk/rancangan memiliki tingkat relativitas yang lebih baik dibandingkan dengan referensinya. Tabel 4 merupakan rincian part pada konsep III, serta hasil rancangan yang ditunjukkan pada Gambar 4.

\section{Design Analysis}

Pada perancangan kali ini ada beberapa acuan atau landasan yang digunakan dalam penentuan ukuran, yaitu melalui unit existing seperti liquid container dan penggunaan antropometri. Penentuan ukuran alat bantu ini melengkapi spesifikasi need statement yang diharapkan penggunanya.

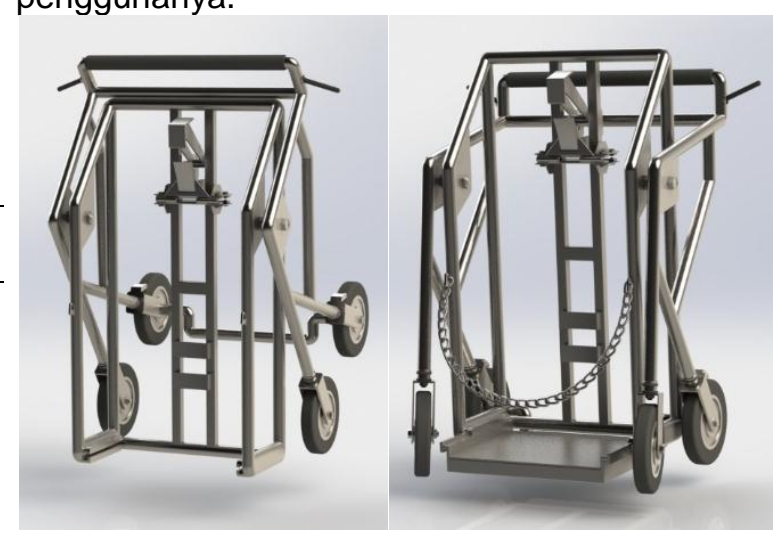

Gambar 4. Alat bantu usulan

Alat bantu usulan ini terdiri dari 4 kelompok komponen utama, yaitu external body (badan penggerak), internal body (badan utama), clamp, dan wheels. Cara kerja dari alat bantu ini adalah dengan operator meletakan liquid container di bagian dalam badan utama. Liquid container diposisikan sedekat mungkin hingga menyentuh 
sandarannya yang berada di bagian bawah badan utama. Saat sudah sesuai, clamp, yang terdiri dari penahan (terletak di bawah bagian depan clamp) dan penjepit (berbentuk seperti panah), disesuaikan pada tepi atas liquid container sampai kedua bagian clamp tersebut mencapit tutup dan tepian dari liquid container. Posisi clamp dapat disesuaikan ketinggiannya serta terdapat beberapa pilihan jarak penjepit untuk menyesuaikan liquid container yang diangkut. Setelah itu, kaki diletakkan pada pedal yang berada di antara kedua roda belakang pada alat. Saat operator meletakkan kakinya, handle harus dipegang agar alat bantu dapat stabil. Setelah genggaman cukup stabil, kaki mendorong pedal ke depan sehingga roda akan ikut bergerak ke depan. Memegang handle juga merupakan upaya untuk mengontrol pergerakan roda ke depan tersebut. Saat roda bergerak ke depan, maka lambat laun badan utama akan terangkat sehingga liquid container sudah tidak lagi menyentuh lantai. Roda akan berhenti bergerak ke depan saat kondisi roda sudah sejajar dan pedal telah tertahan oleh bagian bawah badan utama. Untuk pengamanan tambahan, pengguna dapat menggunakan rantai pada bagian depan badan utama dan penyangga stainless steel (bottom horseblock) pada bagian bawahnya. Alat bantu pun dapat didorong dan dioperasikan menuju tempat tujuan. Alat bantu ini memiliki dua rem tangan untuk memberhentikan masing-masing dari kedua roda belakang. Tuas dapat diangkat untuk mengunci roda dan dapat diturunkan untuk membuatnya bergerak kembali. Sehingga, setelah rancangan selesai dibuat, maka dilakukan analisis spesifikasi teknis pada rancangan usulan yang ditunjukkan pada Tabel 5.

Tabel 5. Spesifikasi teknis hasil rancangan

\begin{tabular}{|c|c|c|c|}
\hline \multicolumn{2}{|c|}{ Metrik Produk } & Nilai & Satuan \\
\hline & Panjang $\mathrm{MH}$ & 97,1 & $\mathrm{~cm}$ \\
\hline DimensI & Lebar $\mathrm{MH}$ & 74 & $\mathrm{~cm}$ \\
\hline & Tinggi $\mathrm{MH}$ & 114 & $\mathrm{~cm}$ \\
\hline Skor MS & Skor REBA & $6 ; 2 ; 3$ & poin \\
\hline SKOr IVISDS & Skor WSC & Low & kategori \\
\hline Bobot $\mathrm{MH}$ & & 66,76 & $\mathrm{~kg}$ \\
\hline Setup time & & 7 & tahap \\
\hline
\end{tabular}

Pada simulasi kali ini, terdapat tiga aktivitas yang terlibat dalam penggunaan alat bantu usulan, yaitu aktivitas mendorong pedal, mendorong alat bantu, dan berjalan sambil mendorong alat bantu. Sehingga, dilakukan tiga simulasi untuk menilai postur operator yang terlibat. Gambar 5 berikut ini merupakan hasil simulasi atau peragaan postur pada software Catia. Sehingga nilai postur yang didapatkan ditunjukkan pada Tabel 6

Hasil simulasi REBA pada Tabel 6 telah menunjukan pengurangan nilai risiko MSDs yang dapat dilihat dari berkurangnya nilai REBA pada alat bantu usulan terhadap aktivitas existing-nya. Seluruh aktivitas yang dilakukan pada penggunaan alat bantu usulan menghasilkan nilai REBA yang lebih kecil. Pada aktivitas mendorong pedal mendapatkan nilai REBA sebesar 6 poin. Hal ini menandakan bahwa aktivitas berisiko sedang serta membutuhkan investigasi lebih lanjut. Namun aktivitas ini hanya membutuhkan waktu yang sebentar, tidak lebih dari $10 \%$ dari total waktu yang dibutuhkan. Pada aktivitas mendorong alat bantu mendapatkan nilai REBA sebesar 2 poin dan aktivitas berjalan sambil mendorong alat bantu mendapatkan nilai REBA sebesar 3 poin. Hal ini menandakan bahwa aktivitas yang dilakukan memiliki risiko rendah serta perubahan mungkin diperlukan.
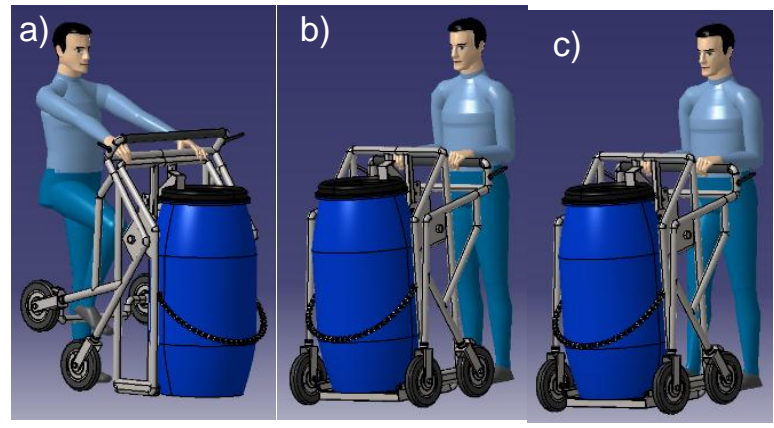

Gambar 5. Hasil simulasi aktivitas:

a) mendorong pedal; b) mendorong alat bantu;

c) berjalan sambil mendorong alat bantu

Tabel 6. Perbandingan skor REBA dan WSC

\begin{tabular}{lcc}
\hline \multicolumn{1}{c}{ Aktivitas } & REBA & WSC \\
\hline $\begin{array}{l}\text { Existing } \\
\begin{array}{l}\text { Mendorong dengan } \\
\text { tangan kosong }\end{array}\end{array}$ Usulan & & $\begin{array}{c}\text { Risiko } \\
\text { sedang }\end{array}$ \\
$\begin{array}{l}\text { Mendorong pedal } \\
\text { Mendorong alat bantu }\end{array}$ & 6 & \\
$\begin{array}{l}\text { Berjalan sambil } \\
\text { mendorong alat bantu }\end{array}$ & 3 & Risiko \\
\hline
\end{tabular}

Hasil simulasi WSC juga menunjukan pengurangan nilai risiko MSDs yang dapat dilihat dari berkurangnya nilai WSC pada alat bantu usulan. Aktivitas yang dilakukan pada penggunaan alat bantu usulan menghasilkan nilai WSC yang lebih kecil. Nilai WSC yang didapatkan adalah risiko rendah terhadap paparan MSDs pada kategori overall work environment. Pada penilaian WSC usulan ini 
diasumsikan bahwa aktivitas tidak sulit dan tidak membuat penggunanya terbebani.

\section{KESIMPULAN}

Berdasarkan hasil analisis ergonomi REBA dan WSC pada penggunaan alat bantu usulan, didapatkan aktivitas pertama adalah mendorong pedal yang menghasilkan skor REBA sebesar 6 poin. Skor tersebut turun 3 poin atau 33,3\% lebih baik dari aktivitas existing. Aktivitas kedua adalah mendorong alat bantu yang menghasilkan skor REBA sebesar 2 poin. Skor tersebut turun 7 poin atau $77,8 \%$ lebih baik dari aktivitas existing. Aktivitas ketiga adalah berjalan sambil mendorong alat bantu yang menghasilkan skor REBA sebesar 3 poin. Skor tersebut turun 6 poin atau $66,7 \%$ lebih baik dari aktivitas existing. Nilai WSC yang didapatkan adalah risiko rendah terhadap paparan MSDs berdasarkan kategori overall work environment. Nilai ini lebih kecil dibandingkan nilai existing sebelumnya, yaitu risiko sedang pada aktivitas existing. Penelitian ini dapat dilanjutkan dengan melakukan analisis lanjutan terhadap rancangan alat bantu yang dapat berupa analisis material dan analisis finansial.

\section{NOMENKLATUR}

$\begin{array}{ll}\text { REBA } & \text { : Rapid Entire Body Assessment } \\ \text { WSC } & : \text { Washington State Checklist } \\ \text { MSDs } & : \text { Musculoskeletal Disorders } \\ \text { WIP } & : \text { Work In Process } \\ \text { ILO } & : \text { International Labour Organization } \\ \text { MH } & : \text { Material Handling } \\ \mathrm{cm} & : \text { centimeter } \\ \mathrm{kg} & : \text { kilogram }\end{array}$

\section{DAFTAR PUSTAKA}

[1] G. B. B. Vieira, G. S. Pasa, M. B. N. do O. Borsa, G. S. Milan, and A. Pandolfo, "Materials Handling Management: A Case Study," J. Oper. Supply Chain Manag., vol. 4, no. 2, pp. 19-30, Dec. 2011, doi: 10.12660/joscmv4n2p19-30.

[2] M. Gentzler and S. Stader, "Posture stress on firefighters and emergency medical technicians (EMTs) associated with repetitive reaching, bending, lifting, and pulling tasks," Work, vol. 37, no. 3, pp. 227-239, 2010, doi: 10.3233/WOR2010-1075.

[3] S. Drisya, B. B. Das, and R. Parida, "Ergonomic Evaluation of Bar Benders in Construction Industry," Singapore: Springer, 2018, doi: 10.1007/978-981-105457-0_6.

[4] S. Hignett and L. McAtamney, "Rapid
Entire Body Assessment (REBA)," Appl. Ergon., vol. 31, no. 2, pp. 201-205, Apr. 2000, doi:

[5] A. Coyle, "Comparison of the Rapid Entire Body Assessment and the New Zealand Manual Handling'Hazard Control Record', for assessment of manual handling hazards in the supermarket industry," Work, vol. 24, no. 2, pp. 111-116, 2005. available

at: https://content.iospress.com/articles/work/ wor00408.

[6] Ontario Health and Safety Associations, MSD Prevention Toolbox: More on Inddepth Risk Assessment Methods. Ontario: OHSCO, 2010, available at: https://www.whsc.on.ca/Files/Resources/ Ergonomic-Resources/MSD-PreventionToolbox-Part-C-In-Depth-Risk-

Assess.aspx.

[7] V. Raja and K. J. Fernandes, Reverse engineering: an industrial perspective. London: Springer Science \& Business Media, 2007, available at: Google Scholar.

[8] D. Tang, R. Zhu, X. Chen, T. Zang, and R. Xu, "Functional Reverse Engineering for Re-creation Design," in Proceedings of the 6th CIRP-Sponsored International Conference on Digital Enterprise Technology, Springer, 2010, pp. 185-195. doi: 10.1007/978-3-642-10430-5_14.

[9] Y.-J. Chang, T. D. Nguyen, M. Finkbeiner, and J. Krüger, "Adapting Ergonomic Assessments to Social Life Cycle Assessment," Procedia CIRP, vol. 40, pp. 91-96, 2016, doi: 10.1016/j.procir.2016.01.064.

[10] K. N. Otto and K. L. Wood, "Product Evolution: A Reverse Engineering and Redesign Methodology," Res. Eng. Des., vol. 10, no. 4, pp. 226-243, Dec. 1998, doi: $10.1007 / \mathrm{s} 001639870003$.

[11] X. Sun, R. Houssin, J. Renaud, and M. Gardoni, "A review of methodologies for integrating human factors and ergonomics in engineering design," Int. J. Prod. Res., pp. 1-16, 2018, doi: 10.1080/00207543.2018.1492161.

[12] G. Salvendy, Handbook of human factors and ergonomics. New Jersey: John Wiley \& Sons, 2012, available at: Google Scholar.

[13] E. Grandjean and K. H. E. Kroemer, Fitting the task to the human: a textbook of occupational ergonomics. Philadelphia: CRC press, 1997, available at: Google 
Scholar.

[14] N. Sultana, M. A. H. Mian, and M. G. Rubby, "Risk and Exposure of Musculoskeletal Disorders among Dental Surgeons Working in Dhaka City," Updat. Dent. Coll. J., vol. 9, no. 1, pp. 3-7, Apr. 2019, doi: 10.3329/updcj.v9i1.41199.

[15] I. Dianat, J. Molenbroek, and H. I. Castellucci, "A review of the methodology and applications of anthropometry in ergonomics and product design," Ergonomics, vol. 61, no. 12, pp. 16961720, Dec. 2018, doi: 10.1080/00140139.2018.1502817.

[16] D. K. Kushwaha and P. V Kane, "Ergonomic assessment and workstation design of shipping crane cabin in steel industry," Int. J. Ind. Ergon., vol. 52, pp. 29-39, Mar. 2016, doi: 10.1016/j.ergon.2015.08.003.

[17] T. Lin, A. Ekanayake, L. S. Gaweshan, and Z. A. Hasan, "Ergonomics product development of over bed table for bedridden patients," Comput. Aided. Des. Appl., vol. 13, no. 4, pp. 538-548, Jul. 2016,

doi: 10.1080/16864360.2015.1131550.

[18] I. Dianat and A. Salimi, "Working conditions of Iranian hand-sewn shoe workers and associations with musculoskeletal symptoms," Ergonomics, vol. 57, no. 4, pp. 602-611, Apr. 2014, doi: 10.1080/00140139.2014.891053.

[19] K. T. Ulrich, Product design and development. Tata McGraw-Hill Education, 2003, available at: Google Scholar.

[20] W. Karwowski, Anthropometry for The Needs of Rehabilitation. CRC Press, 2006, doi: 10.1201/9780849375477.

[21] A. Lesmana, A. Kusnayat, and $M$. Rahayu, "Perancangan Alat Pengangkut Bahan Bakar Kayu Custom Menggunakan Pendekatan Reverse Engineering (studi Kasus Pt. Xyz)," eProceedings Eng., vol. 4, no. 2, pp. 2843-2849, 2017, available at:

http://202.134.6.251/index.php/engineerin g/article/view/1228.

[22] A. Kusnayat, S. Martini, E. Shabrina, and A. Rizal, "Application of Reverse Engineering for Modified Anchor Impeller," World Sci. News, vol. 112, pp. 14-23, 2018 available

at: http://psjd.icm.edu.pl/psjd/element/bwmet a1.element.psjd-1ae33f41-a2fb-4650b5a9-5ab6e7e5b009.

[23] A. Gameros, L. De Chiffre, H. R. Siller, J.
Hiller, and G. Genta, "A reverse engineering methodology for nickel alloy turbine blades with internal features," CIRP J. Manuf. Sci. Technol., vol. 9, pp. 116-124, May 2015, doi: 10.1016/j.cirpj.2014.12.001.

[24] N. Al Hadid, A. Kusnayat, and M. Rahayu, "Perancangan Ulang Bak Penampung Bahan Baku Pakan Ternak Menggunakan Metode Reverse Engineering Untuk Mengurangi Risiko Kecelakaan Kerja," eProceedings Eng., vol. 4, no. 2, pp. 2720-2730, 2017, available at: https://libraryeproceeding.telkomuniversity .ac.id/index.php/engineering/article/view/1 168. 